\title{
ISOTROPIC POINTS ON GLACIERS
}

\author{
By J. F. NYE
}

(H. H. Wills Physics Laboratory, University of Bristol, Bristol BS8 1TL, England)

ABstract. Two isotropic points measured by Meier and others (1985) on Columbia Glacier, Alaska, are examined. The pattern classification of the upper one is on the borderline between monstar and lemon, and this is traced to the fact that the variation of strain-rate in the longitudinal direction is approximately equal to that in the transverse direction, contrary to the assumption made in Nye (1983). The conditions for the lower isotropic point to have the star pattern, as observed, are believed to be typical for a glacier that ends in an ice cliff, like this one, which calves icebergs. Where, as in this case, there is only a small transverse velocity, the isotropic points on a glacier must nearly coincide with stationary points for the speed, and these are almost always either maxima or saddles, alternating. The maxima correspond to lemon or monstar patterns, and the saddles to star patterns.

RÉsumÉ. Points isotropiques sur les glaciers. Deux points isotropiques mesurés par Meier et alter (1985) sur le Columbia Glacier, Alaska, sont examinés. La caractéristique de classification de celui de l'amont se situe à la limite entre le Monstar et le Citron, dû au fait que la variation de taux de déformation dans la direction longitudinale est approximativement égale à celle de la direction transversale, à l'opposé de l'hypothèse formulee par Nye (1983). Les conditions pour le point aval de posséder les caractéristiques de l'étoile, selon les observations, sont plutôt attribuées au

\section{INTRODUCTION}

Meier and others (1985) have recently published a remarkably comprehensive photogrammetric study of Columbia Glacier, Alaska, which includes (as plate 7) a detailed map of its lower part showing the trajectories of principal strain-rate on the surface, averaged over the measurement year. The pattern of trajectories displays two isotropic points and it is interesting to compare them with theoretical predictions made for glaciers in general (Nye, 1983). The trajectories of the lesser (more compressive) principal strain-rate are shown schematically in Figure 1, with the isotropic points denoted $P_{1}$ and $P_{2}$.

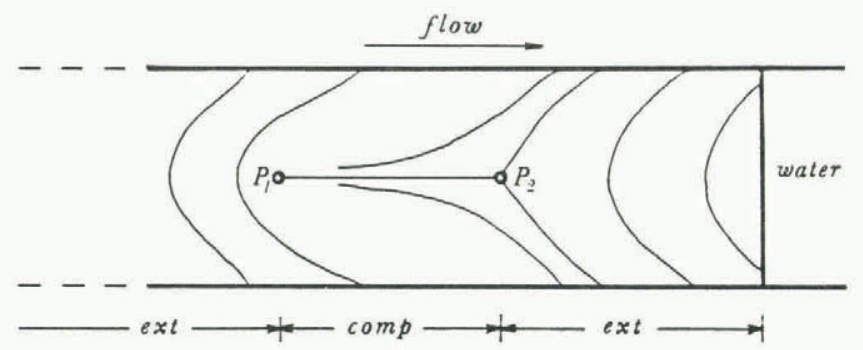

Fig. 1. Schematic plan view of the lower part of Colombia Glacier showing the trajectories of the lesser (more compressing) principal strain-rate and the two isotropic points $P_{1}$ and $P_{2}$. Regions of longitudinal extension and compression are indicated. fait que le glacier se termine par une falaise de glace, comme c'est le cas ici et qui vèle des icebergs. Dans ces conditions il existe seulement une faible vitesse transversale et les points isotropiques sur un glacier doivent plutôt coincider avec des points stationnaires en vitesses, qui sont presque toujours ou des maxima ou des selles, alternativement. Les maxima correspondent au type Citron ou Monstar et les selles à celui de l'étoile.

ZUSAMmENFASSUNG. Isotropische Punkte auf Gletschern. Es werden zwei isotropische Punkte untersucht, die von Meier und anderen (1985) auf dem Columbia Glacier in Alaska vermessen wurden. Das Klassifikationsmuster des höher gelegenen fällt auf die Grenzlinie zwischen dem "Monstar"- und dem "Lemon"-Typ; dies lässt sich auf die Tatsache zurückführen, dass die Änderung der Spannung in Längsrichtung etwa gleich der in Querrichtung ist, im Gegensatz zu der Annahme von Nye (1983). Die Voraussetzungen für das beobachtete "Star"-Muster des unteren isotropischen Punktes werden als typisch für einen Gletscher angesehen, der in einem Eiskliff endet, - so wie eben dieser, der Eisberge kalbt. Wo, wie in diesem Fall, eine nur geringe Quergeschwindigkeit vorliegt, müssen die isotropischen Punkte fast mit den Punkten stationärer Geschwindigkeit zusammenfallen, und diese sind fast immer abwechselnd entweder Scheitel- oder Sattelpunkte. Die Scheitelpunkte gehören zum "Lemon"- oder "Monstar"-Typ, die Sattelpunkte zum "Star"-Typ.

\section{THE UPPER ISOTROPIC POINT $\mathbf{P}_{1}$}

This point is associated with a change from longitudinal extension to longitudinal compression in the lower part of the glacier. From the observations, Meier and others (1985) concluded that the pattern at this point is lemon (L) (Fig. 2), in contrast to the theoretical prediction that it would be monstar (M). The essential difference

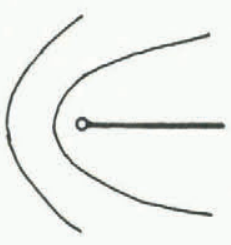

$L$

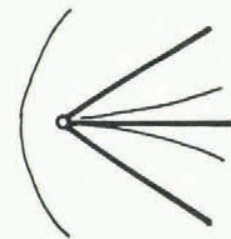

$M$

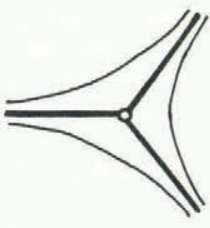

$S$
Fig. 2. The three possible patterns of one set of principal strain-rate trajectories around an isotropic point: $L=$ lemon $\quad\left(\right.$ index $\left.+\frac{1}{2}\right) ; \quad M=$ monstar $\quad$ (index $\left.+\frac{1}{2}\right)$; $S=$ star (index $-\frac{1}{2}$ ). The orthogonal trajectories are obtained by rotating each pattern through $180^{\circ}$.

between the lemon and monstar patterns is that the latter has three straight-line trajectories running into the isotropic point, while the former has only one. Observationally, it can be very difficult to distinguish between the two patterns and I believe that, given the density of data points 
used in the survey of Columbia Glacier, either interpretation is possible.

To explain this in more detail let me take a coordinate system, as in my paper, with origin at $\mathrm{P}_{1}$, with $x$ longitudinal and increasing down-glacier, and with $y$ transverse, and put

$$
a=-\frac{\partial \dot{\epsilon}_{x x}}{\partial x} \text { and } b=-\frac{\partial \dot{\epsilon}_{x y}}{\partial y}
$$

where $\dot{\boldsymbol{\epsilon}}_{x x}$ and $\dot{\boldsymbol{\epsilon}}_{x y}$ are tensor strain-rate components, both derivatives being taken at the origin. The strain-rate tensor is then approximated in the neighbourhood of $P_{1}$ by

$$
\dot{\boldsymbol{\epsilon}}=\left[\begin{array}{cc}
E-a x & -b y \\
-b y & E
\end{array}\right]
$$

where $E$ is the common value of $\dot{\epsilon}_{x x}$ and $\dot{\epsilon}_{y y}$ at $\mathrm{P}_{1}$. Note that this approximation includes only the two most important linear variations of the components. The monstar prediction was based on the assumption that, in most glaciers, $0<a<b$. At $\mathrm{P}_{1}$ on Columbia Glacier there is approximate equality between the two dominant derivatives, $0<a \approx b$, and consequently the point is borderline monstar-lemon.

If the three straight lines of the monstar pattern are opened out as far as the data allow, the two outer lines make angles of $\pm 12^{\circ}$ with the $x$-axis. From the formula $\tan ^{-1} \sqrt{\{1-(a / b)\}}=12^{\circ}$, this corresponds to $a / b=0.95$. Thus, if the data are interpreted most favourably for the monstar pattern, the condition $a<b$ is only just satisfied. As $a / b$ passes through 1 , the three straight lines close up and the pattern becomes lemon. As Meier and others (1985) indicated, the data can also be fitted with a lemon pattern, corresponding to $a>b$. My conclusion is that one cannot be certain about the pattern category. In a long, narrow glacier one would expect transverse variations, represented by $b$, to dominate longitudinal variations, represented by $a$, and hence a clear monstar pattern. The lower part of Columbia Glacier is evidently too wide for this.

\section{THE LOWER ISOTROPIC POINT $\mathbf{P}_{\mathbf{2}}$}

Although much of Columbia Glacier has its bed below sea-level, it is grounded throughout its length, ending in an ice cliff standing in the sea and producing icebergs. The lower isotropic point $P_{2}$ is associated with the change from longitudinal compression to extension in the terminal part of the glacier. Thus, taking the origin now at $P_{2}$, we have $a<0<b$. The index discriminant given by Thorndike and others (1978) reduces to $D_{1}=a b$, and is therefore negative, giving index $-\frac{1}{2}$. The line discriminant is $D_{\mathrm{L}}=12 b(b-a)^{3}$ and is therefore positive, indicating three lines. The theoretical pattern is therefore star, in agreement with the observations. We see that the star pattern is inevitable if the arrangement of signs is $a<0<b$. Drag from the valley sides ensures that $0<b$ in the centre of the glacier (although not necessarily near the edges), while the absence of restraint at the terminus must surely entail $a<0$. Thus the star pattern should be universal for these conditions.

\section{THE CONTOUR CLASSIFICATION}

The third kind of classification for an isotropic point, in addition to index $\left( \pm \frac{1}{2}\right)$ and line ( 1 or 3$)$, relates to the shape of the contours showing the magnitudes of the two principal strain-rates near the point. These form two intersecting families of curves. Generically, both families are ellipses or both families are hyperbolas. For the tensor in Equation (1) the contour discriminant reduces to $D_{\mathrm{C}}=0$, showing that we have the borderline, non-generic, case where the contours are parabolas. This is structurally unstable, and the perturbations represented by linear terms omitted from Equation (1), which must be present, will change the contours into either very elongated ellipses or hyperbolas. The observations on Columbia Glacier cannot be expected to make such fine distinctions, either for $P_{1}$ or $\mathbf{P}_{\mathbf{2}}$.
However, as shown in Nye (1983), the contour classification for stress, rather than strain-rate, is structurally stable. The contour discriminant has the same sign as $-a^{2} b^{2}$, and is therefore unconditionally negative (unless $a=b=0$ ). This indicates hyperbolic, rather than elliptic, contours for the magnitudes of the principal stresses around both $P_{1}$ and $\mathbf{P}_{2}$.

We may note that $P_{1}$ and $P_{2}$ are special, as isotropic points, in that $E \approx 0$; that is, $\dot{\epsilon}_{x x}=\dot{\epsilon}_{y y} \approx 0$ at the points themselves. This means that they occur nearly, but not exactly, at the two places (on the line defined by $\dot{\epsilon}_{x y}=0$ ) where the longitudinal strain-rate $\dot{\epsilon}_{x x}$ changes sign. Thus, $P_{1}$ is very close to the point where longitudinal extension changes to compression, and $P_{2}$ is very close to the point where it changes back to extension.

\section{STATIONARY POINTS FOR THE SPEED}

Meier and others (1985) also showed, as plate 6, a contour map of the speed of the lower part of Columbia Glacier, averaged over the measurement year. It is notable that the two isotropic points $P_{1}$ and $P_{2}$ that they show in plate 7 are close to, but not coincident with, a maximum and a saddle point, respectively, in the contours of speed. If we take a local coordinate system with origin at the isotropic point and if we assume $v=0$, then the condition for a stationary point in the speed $|u|$, namely

$$
\frac{\partial u}{\partial x}=\frac{\partial u}{\partial y}=0 \quad(\text { since } u>0),
$$

is identical with that for an isotropic point, which is

$$
\frac{\partial u}{\partial x}=\frac{\partial v}{\partial y}, \quad \frac{\partial u}{\partial y}=-\frac{\partial v}{\partial x} .
$$

Since, if $v$ were uniformly zero, the stationary points for speed would coincide precisely with the isotropic points, any small lack of coincidence must be attributed to the presence of a small $v$ component. The stationary points for speed and the isotropic points are individually structurally stable, but the coincidences between them are only approximate because they are unstable to perturbations of the transverse velocity.

Plate 5 of Meier and others (1985) shows contours for the speed over the entire Columbia Glacier system, which contains several tributaries. There are about 34 points where the speed is stationary, some 14 of which are on the main ice stream, and they are all maxima or saddles, with no minima. This is explained by the fact that $\partial^{2} u / \partial y^{2}$ is almost always negative, while $\partial^{2} u / \partial x^{2}$ can be positive (saddle) or negative (maximum). If we neglect $v, \partial^{2} u / \partial x^{2}=-a$ and $\partial^{2} u / \partial y^{2}=-2 b$. The analysis of $P_{1}$ and $P_{2}$ then suggests that these 34 stationary points for speed are close to 34 isotropic points (on the measurement scale adopted), the maxima corresponding to lemons or monstars and the saddles to stars. On any one ice stream, maxima for speed must alternate with saddles (Fig. 3) and, likewise, lemons or monstars must alternate with stars. All the isotropic points will have hyperbolic, rather than elliptic, contours of magnitude of principal stress.

(a)

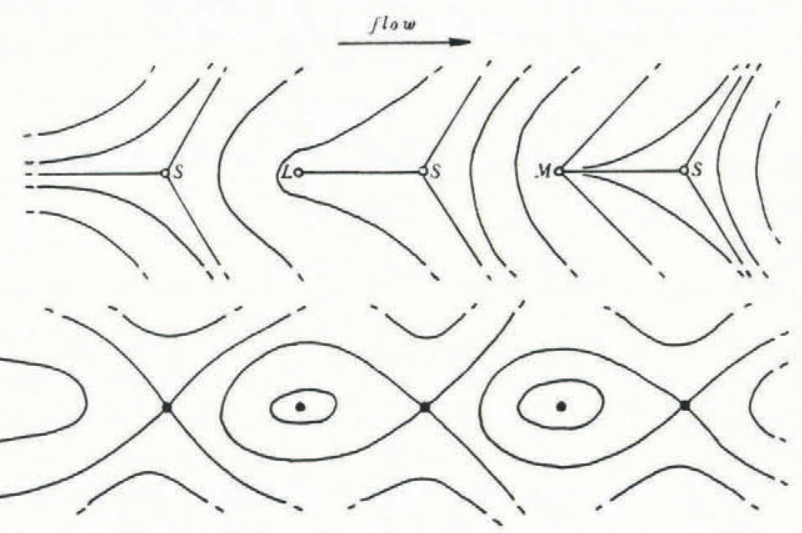

Fig. 3. (a) Schematic plan view to show the alternation of lemon $(L)$ or monstar $(M)$ with star $(S)$ along any one ice stream. (b) The corresponding contours of glacier speed. 


\section{REFERENCES}

Meier, M.F., and others. 1985. Photogrammetric determination of surface altitude, terminus position, and ice velocity of Columbia Glacier, Alaska. (Studies $\rightarrow$ of Columbia Glacier, Alaska), by M.F. Meier, L.A. Rasmussen, R.M. Krimmel, R.W. Olsen, and D. Frank. U.S. Geological Survey. Professional Paper 1258-F.
Nye, J.F. 1983. Monstars on glaciers. Journal of Glaciology, Vol. 29 , No. 101 , p. 70-77.

Thorndike, A.S., and others. 1978. The structure and evolution of flow fields and other vector fields, by A.S. Thorndike, C.R. Cooley, and J.F. Nye. Journal of Physics, A: Mathematical and General, Vol. 11, No. 8, p. 1455-90.

A. received 18 Anril 1986 and in revised form 13 June 1986 